$S=k \log \Omega$ ) surely did not foresee this.

Morowitz offers some agreeable literary diversions and his thermodynamite's view of the passage in Ulvsses, in which Leopold Bloom boils a kettle for his shaving water, deserves to be preserved. $\mathrm{He}$ is also rather good on dentists: he enjoys the "intellectual and aesthetic pleasure" of feeling a craftsman at work in his mouth. (Bernard Shaw took the same view: there was nothing more soothing, he wrote in one of his music criticisms, after a harrowing series of recitals, than to have one's teeth drilled by a finely-skilled hand.) There is much in this collection to entertain. sometimes to annoy and only occasionally to bore.

David Quammen disarmingly confesses to being a dilettante rather than a scientist, "a haunter of libraries and a snoop". He writes natural history in an unmistakably American style and is given to apostrophizing his reader in sporting metaphors. "Truly", he says, speaking of the larger kind of sea cucumber, "these guys are out in left field". This, I own, stretches my tenuous grasp of baseball. And what, for that matter, is this Hostess Twinkie, that a seal allegedly resembles in section?

The sea cucumber opens Quammen's collection, and its trials are considerable: the tiny parasitic candiru fish, for instance, enters and leaves the cucumber with impunity by way of the nether passage, lingering only to feed on its vitals. "You'd think", Quammen exclaims, "the little bugger was selling encyclopaedias". Well, these are not the lapidary periods of a Medawar or Gould; but we do learn how the resourceful cucumbers deal with the situation when they eventually weary of the tiresome intruder: they evert themselves and "blast their own gut and internal organs out through their own anus". Humans are denied this recourse, and, says Quammen, when the candiru enters the urethra it lodges there, its spines facing backwards, and the only alternative to death by blood poisoning is amputation. Beginning to feel faint, I passed on to the next story, which is about bats, and here was rewarded by an account of a scheme by the American military during the Second World War to subdue the Japanese by dropping bats, each fitted with a napalm bomb and a little parachute, on their cities.

Quammen's book is full of strange information about animals and their habitat, about Tycho Brahe's artificial nose, and other such oddities. His exuberance carries one, sometimes unwillingly, along. $\mathrm{He}$ has a penchant for the poetry of Donne, and an informed concern for wildlife and the environment that is altogether heartening; his book deserves every success.

Walter Gratzer is in the Medical Research Council Cell Biophysics Unit, Kings College London (KQC), 26-29 Drury Lane, London WC2B $S R L, U K$.

\section{Behind the scenes in the fight on tropical diseases}

\section{Adetokumbo O. Lucas}

From the Face of the Earth*. By June Goodfield. André Deutsch: 1985. Pp. 256. f10.95.

THE public exhibit an insatiable hunger for news about medicine and the medical sciences. In this book June Goodfield provides a five-course offering to feed the layman's appetite for "stories of medical achievement". As popular science, it translates into everyday language scientific information that is often obscured by jargon. The story telling is enlivened by taking the reader behind the scenes of scientific events - we read not only of dedication and the determination to succeed, but of personal disputes, divorce. dementia and other such human problems.

The first story about Kuru contains all the excitement of a strange disease, uniformly fatal among the sufferers, with a maximal impact on women and children and threatening to wipe out a whole community. This account highlights the role of those who finally solved the mystery. At the top of the list is Carleton Gajdusek. the deserved winner of a Nobel prize for identifying the cause of Kuru and for the discovery of slow viruses as causes of human disease. June Goodfield, however, notes but does not stress the point that control of Kuru in Papua New Guinea did not result directly from the outstanding biomedical and behavioural research which she so vividly describes. Rather, the decline in the incidence of Kuru apparently stemmed from action taken by some person(s) unnamed, who, in the $1950 \mathrm{~s}$, forced a cultural change in the ritual method of disposing of the dead. Who,

*In the United States Quest for the Killers, published by Birkhäuser price $\$ 24.95$. one wonders, were these faceless persons? What was their motive? Was it mere abhorrence of a strange cultural practice. or did they somehow intuitively sense that such practices could have fatal consequences?

The Kuru story illustrates the fall-out effect by which research on a specific problem can gencrate new knowledge of fundamental importance and unexpected benefit in other areas. Thus the work in Papua New Guinea has brought to Europe and North America new insights to diseases of local interest, such as GerstmannStraussler Syndrome and CreuzfeldtJakob Disease.

Discipline, dedication and imaginative resourcefulness are the main ingredients of the next story on hepatitis B vaccine. Illustrated here is the point that the identification of the appropriate risk groups is an essential stock-in-trade of the epidemiologist. from classical studies on scurvy among English sailors, to research into cancer of the lung among smokers.

"The Three Valleys of St Lucia" deals with a large operational research programme aimed at comparing strategies for the control of schistosomiasis. Unlike Kuru, a unique disease in an island population, schistosomiasis is widespread in the tropics, affecting some 200 million people. It is not new - its eggs have been found in an Egyptian mummy - but it presents a fresh challenge where projects such as irrigation schemes and man-made lakes result in expansion of the population of the vector snails, an increase in manwater contacts, and thus intensification and broadening of the distribution of the disease.

The St Lucia story well illustrates the practical questions that need to be answered in translating theoretical options into effective strategies. And, again, the research provided answers that were useful not only on St Lucia but also in other areas. Recently, the World Health Organization proposed new strategies for the control of schistosomiasis which owe much to the findings at St Lucia, updated to take note of recent advances in technol-

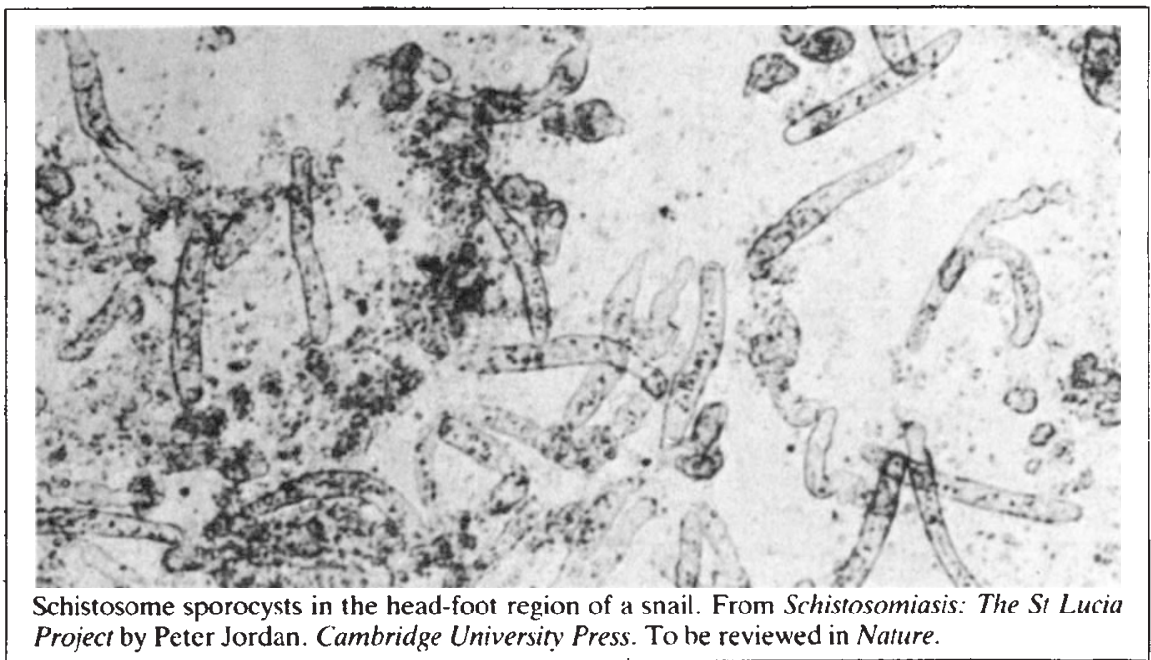


ogy, in particular the availability of a new, well-tolerated drug.

The chapter on leprosy is interesting, but perhaps premature in comparison with the other stories. It tells of the search for a vaccine; but while much progress has been made over the past decade we are still far from finding a vaccine of proven efficacy for operational use.

The last story, on the fight against smallpox, provides a grand finale in that it fully justifies the title of the British edition of the book. This was a unique achievement, the total eradication of a disease that presented a worldwide challenge. Even though Kuru may disappear, one cannot sign its death certificate with the same confidence as was done for smallpox on 8 May 1980 at the World Health Assembly in Geneva. Although there has been some speculation about the feasibility of completely eradicating other infections "from the face of the Earth" - proposed candidates include measles and poliomyelitis - no other disease presents the combination of features which made possible the difficult task of eradicating smallpox.

Most of the data required for epidemiological surveillance of smallpox could be obtained from fairly simple clinical observations of sick patients, and the examination of scars of healed natural infections or vaccination scars. Laboratory help was required in the identification of the small proportion of atypical cases, and for the differentiation of smallpox from other pox diseases. Most other infections present more formidable problems; the clinical features are usually not sufficiently characteristic to permit differential diagnosis on simple clinical examination. and there are usually no pathognomonic scars to identify those who have had previous infections or are protected by immunization.

Apart from satisfying the demand for exciting accounts of medical discoveries, this book and similar ones draw the public into the debate about investment in the biomedical sciences. On the one hand, at times of economic recession, reduction in the budgets for biomedical research often seems a soft option because the venture does not command a powerful constituency. On the other hand, when threatened by the appearance of such problems as Legionnaire's disease and AIDS, people are anxious to know that something is being done to control the scourge. This book shows that breakthroughs do not leap out on the order of clever scientists. It portrays the path to knowledge as a difficult one, more often crossed by disappointments than by the discoveries that come as the final reward for longsustained devotion to science and the improvement of human health.

Aderokunbo O. Lucas is Director of the Special Programme for Research and Training in Tropical Diseases. World Health Organization. 1211 Geneva 27. Switzerland.

\section{Lemons and limes}

\section{Joe Collier}

Drug Discovery: The Evolution of Modern Medicines. By Walter Sneader. Wiley: 1985. Pp.392. Pbk f12.95, \$21.95.

Pharmacologists, physicians and legislators alike are now very wary of assuming that a drug is necessarily a medicine. Whereas a drug is any chemical substance that modifies a biological process, a medicine is that rare drug that can be used in patients to treat disease.

It is this distinction that occupies regulatory authorities (such as the Committee on Safety of Medicines, and the Food and Drug Administration) when licensing drugs for medical use; equally, it is the gap that the pharmaceutical industry strives to bridge so that new products can be marketed. Accordingly, as advances in fields such as biochemistry, genetics, immunology and pharmacology have led to the production of evermore sophisticated drugs, legislators have demanded increasingly detailed information about them before they will consider granting a licence. This balance now dominates the development of new therapeutic agents, and it is to this end that industry labours to discover how new drugs are absorbed, metabolized and excreted, how they should be formulated to be delivered to best advantage, how the dosage frequency should be adjusted to offer the greatest chance of efficacy, and, in longer term trials, the details of safety and efficacy.
Walter Sneader seems to be almost oblivious of these issues which are so central to the title of his book. They neither seem to be a consideration from which he might view the past, nor have they proved worthy of mention as a topic in their own right (and one so admirably dealt with by R.D. Mann in Modern Drug Use: An Enquiry on Historical Principles, published last year by MTP Press).

Instead, Sneader has filled the book with classical information. Each chapter (there are 16 in all) is devoted to a single broad therapeutic category, such as antibiotics, cardiovascular drugs, psychopharmacological agents, and in each the group is traced from the earliest reference to a seminal substance (penicillin, digoxin, Rauwolfia) through to drugs developed in recent history (the date seems to depend on Sneader's interests; inotropic agents stop with digoxin in 1933). The material is mostly in story form, in which the full names and addresses of each and every worker are listed, as are the movements of compounds and ideas between departments, companies and continents. There is an abundance of anecdotal information, clearly written and easy to follow - it is fascinating, for instance, to learn that scurvy returned as a threat to sailors when the trusty lemon juice was replaced by lime; lime juice. which was introduced for reasons of economy, has, we are told, about onequarter of the ascorbutic activity of lemon juice.

Two good reasons for publishing a new history book are that either it reveals fresh information or it analyses history from a

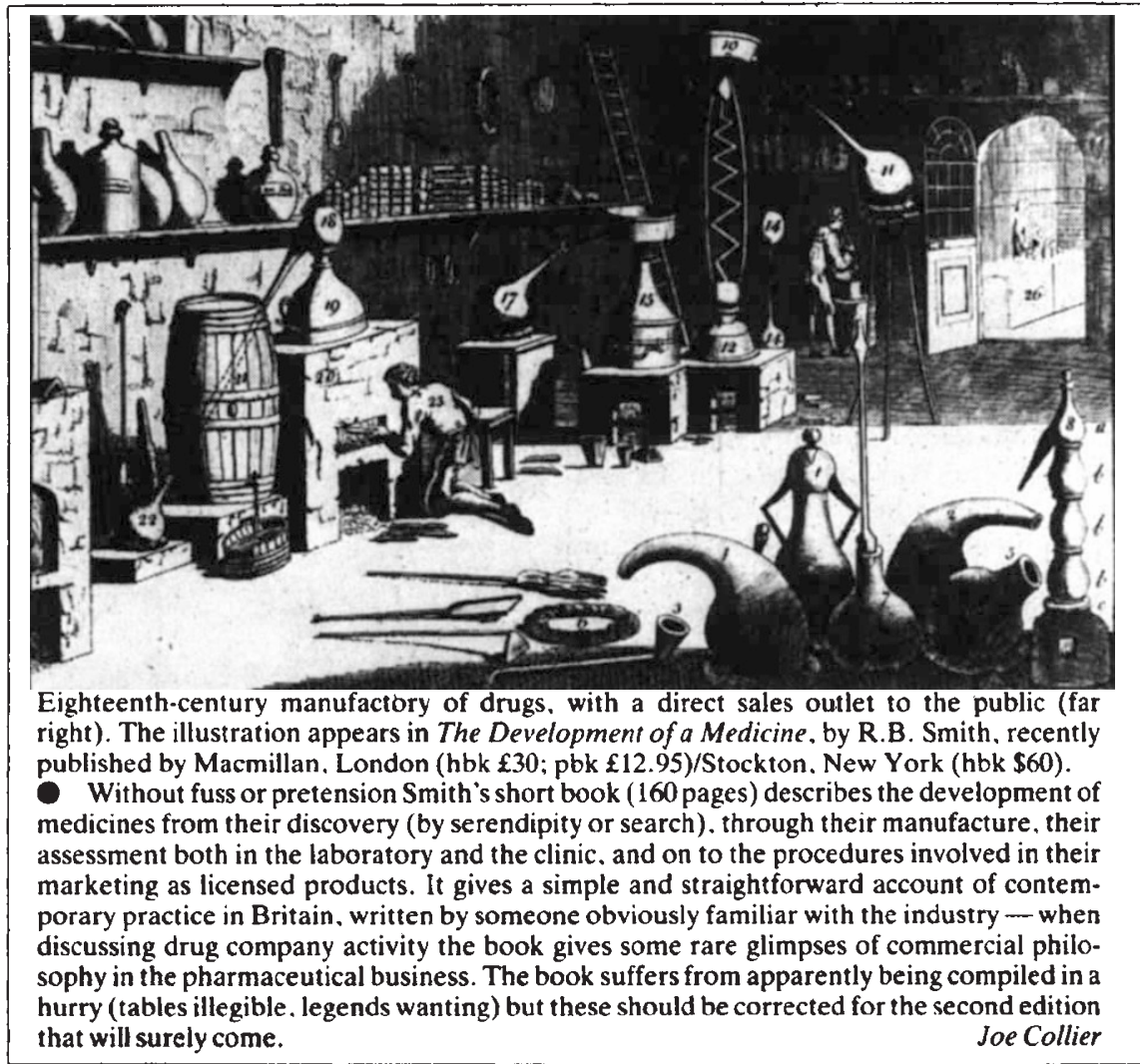

